K. TARETTO

U. RAU

J.H. WERNER

\section{Closed-form expression for the current/ voltage characteristics of pin solar cells}

Institut für Physikalische Elektronik, Pfaffenwaldring 47, 70569 Stuttgart, Germany
Published online: 23 August 2006 • ㄷ Springer-Verlag 2006

The following corrects some typing errors and an analytical miscalculation in the above paper.

Page 866. In the third column, the fifth line in the last paragraph should read 'lengths $L$, since $L=\left(V_{t} \mu \tau\right)^{1 / 2}$,

Page 867. Equation (6) should read

$n(x)=B+C_{2} \exp \left(\lambda_{1} x / W\right)+C_{1} \exp \left(\lambda_{2} x / W\right)$

and (8) should read

$J=2 J(x=0)+2 \int_{0}^{W / 2}\left(\frac{n(x)-n_{0}(x)}{\tau}-G\right) \mathrm{d} x$

Page 868. Equation (12) should read

$n_{\mathrm{id}}^{-1}=V_{t} \frac{\mathrm{d}}{\mathrm{d} V} \ln \left(\frac{J}{J_{0}}\right)$

and (14) should read

$f_{C}=\frac{\exp \left(\lambda_{2} / 2\right)-1}{\lambda_{2} / 2}$.

Figure 3 should be replaced by the following graph:

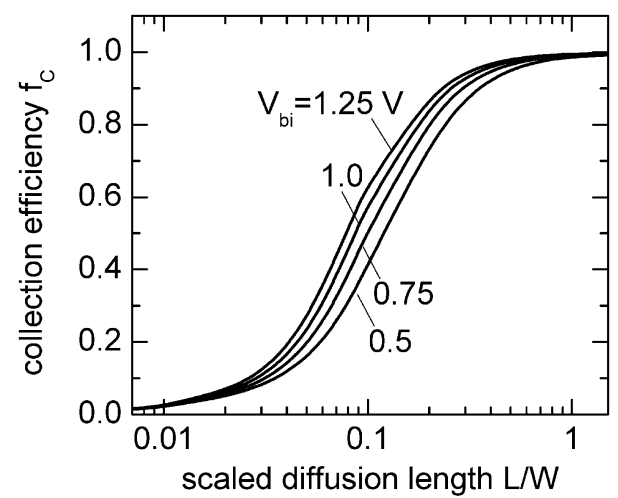

Fax: +49-711-685-7206, E-mail: kurt_taretto@argentinia.com
On page 868 also, in the second column, the first line of the last paragraph should read 'When $L$ tends to zero, $\lambda_{2}$ tends to minus infinity' and, in the same paragraph, the last line should read ' $q G W$ are reached provided $L / W>\mathbf{0 . 3}$ '.

In the third column, the fourth line of the first paragraph should read ' $L / W>\mathbf{0 . 3}$ ' still allows for diffusion.

Page 871. Equation (A.9) should read

$A_{3}=-\lambda_{2}-S_{S}+\left(\lambda_{1}+S_{S}\right) \exp \left(\frac{\lambda_{1}-\lambda_{2}}{2}\right)$.

The authors are grateful to Anas Al Tarabsheh (Institut für Physikalische Elektronik, Universität Stuttgart, Germany) for thoroughly revising our paper.

The orginal article was published in Appl. Phys. A 77, 865-871 (2003)

The online version can be found at

http://dx.doi.org/10.1007/s00339-003-2257-7 